\title{
EDITORIAL
}

\section{Preface: sediment environment and pollution control in China}

\author{
Chengxin Fan ${ }^{1}$
}

Received: 11 August 2021 / Accepted: 11 August 2021 / Published online: 13 September 2021

(C) The Author(s), under exclusive licence to Springer-Verlag GmbH Germany, part of Springer Nature 2021

Sediment is one of the main environmental media in inland waters and the ocean, accumulating more than $90 \%$ of pollutants in lake basins, riverbeds, or the seabed. Located in the intersection area of the hydrosphere, soil lithosphere, and biosphere, the physical, chemical, and biological interactions between sediments and other environmental media are often an important link in the migration and distribution, form change, pollution effect, and final fate of substances in water. In the past 20 years, great progress has been made in the research of sediment environment and pollution control all over the world. In China, remarkable progress has also been made in the role and effects of sediments at the macro and micro scales, the migration of pollutants at the sediment-water interface, the environmental and biogeochemical cycle, the ecological hazard risk of sediments and the environmental quality criteria, the in situ control and remediation of contaminated sediments, and the treatment and utilization of sediments.

This special issue of Journal of Soils and Sediments consists of selected contributions of the 8th China Sediment Environment and Pollution Control Symposium (SEPC2020) held in Nanjing, China, from November 6 to 8, 2020. Professor Wang Peifang (Hohai University) and I served as co-chairs of SEPC2020 in 2020. After the meeting, a guest editorial group was led by Professor Zhang Haihan
(Xi'an University of Architecture \&Technology), assisted by Professor Wang Peifang and Research Professor Yin Hongbin (Nanjing Institute of Geography and Limnology, Chinese Academy of Sciences). From the complete paper reports submitted by the invited oral speakers and poster presenters at the meeting, the guest editors selected 26 articles that appear in this special issue after careful and professional review. The selected papers included in this special issue cover marine and inland water bodies (lakes, reservoirs, and rivers) and research that focuses on sediment environment and biogeochemical mechanisms and effects, bioavailability and eco-environmental risks, and control technologies and effects for sediment pollutant release.

Finally, I would like to thank the efforts of all authors and referees who helped to ensure the quality of this issue. I wish to express gratitude to the editorial team for their agreement to publish these papers related to SEPC2020 and for their continuous and excellent assistance in preparing this special issue.

Publisher's Note Springer Nature remains neutral with regard to jurisdictional claims in published maps and institutional affiliations.

Chengxin Fan

cxfan@niglas.ac.cn

1 Nanjing Institute of Geography and Limnology,

Chinese Academy of Sciences, 73 East Beijing Road,

Nanjing 210008, China 